\title{
GPR44 as a Target for Imaging Pancreatic Beta-Cell Mass
}

\author{
Olof Eriksson ${ }^{1,2}$
}

Published online: 27 June 2019

(C) The Author(s) 2019

\begin{abstract}
Purpose of Review Quantitative markers for beta-cell mass (BCM) in human pancreas are currently lacking. Medical imaging using positron emission tomography (PET) markers for beta-cell restricted targets may provide an accurate and non-invasive measurement of BCM, to assist diagnosis and treatment of metabolic disease. GPR44 was recently discovered as a putative marker for beta cells and this review summarizes the developments so far.

Recent Findings Several small molecule binders targeting GPR44 have been radiolabeled for PET imaging and evaluated in vitro and in small and large animal models. ${ }^{11} \mathrm{C}-\mathrm{AZ} 12204657$ and ${ }^{11} \mathrm{C}-\mathrm{MK}-7246$ displayed a dose-dependent and GPR44-mediated binding to beta cells both in vitro and in vivo, with negligible uptake in exocrine pancreas.

Summary GPR44 represents an attractive target for visualization of BCM. Further progress in radioligand development including clinical testing is expected to clarify the role of GPR44 as a surrogate marker for BCM in humans.
\end{abstract}

Keywords Beta-cell imaging $\cdot$ Islet imaging $\cdot$ Beta-cell mass $\cdot$ GPR44 $\cdot$ PET $\cdot$ Diabetes

\section{Introduction}

Loss of functional beta-cell mass (BCM) is a hallmark feature in both type I and type 2 diabetes (T1D/T2D). Our knowledge on the progressive change in BCM during development of diabetes is currently dependent on biopsy, usually obtained post-mortem. The datasets describing dynamic changes in $\mathrm{BCM}$ in pancreas are therefore often cross-sectional in nature. On the other hand, these are lacking the crucial longitudinal component, evidently needed given the remarkable variation (up to power of 10) in BCM in non-diabetic subjects [1].

Readily accessible plasma markers for beta-cell function, such as insulin, c-peptide, and $\mathrm{HbAlc}$, are dependent on several downstream metabolic pathways and do not correlate well to $\mathrm{BCM}$.

This article is part of the Topical Collection on Immunology, Transplantation, and Regenerative Medicine

Olof Eriksson

olof.eriksson@ilk.uu.se

1 Science for Life Laboratory, Department of Medicinal Chemistry, Uppsala University, Dag Hammarskjölds väg 14C, 3tr, SE-752 37 Uppsala, Sweden

2 Antaros Medical AB, Mölndal, Sweden
The possibility of using medical imaging technology to visualize and accurately measure human and animal BCM has been intensely explored during the last decade [2]. Positron emission tomography (PET) is of particular interest due to the high sensitivity and potential for quantification of this technology. Briefly, suitable molecules may be labeled with unstable nuclides which decay by emission of positrons, i.e., the antiparticle of the electron. When the positron encounters an electron, both particles are annihilated while generating two gamma photons, emitted in opposite directions, which can be detected by a PET scanner with reasonable temporal (seconds) and spatial (millimeters) resolution. The radiolabeled molecule can thus be traced inside a living organism, including humans, following administration. If the labeled molecule binds to a receptor with sufficient affinity and specificity, it is in theory possible to measure the receptor density in a tissue of interest.

Several targets restricted to the beta cells within the pancreas have thus been proposed as potential markers for BCM imaging. More targets than can be discussed under the scope of this review have been suggested [2], but some of the more prominent as well as those evaluated by human PET studies include the vesicular monoamine transporter 2 (VMAT2) [3], the glucagon like peptide-1 receptor (GLP1R) [4], the serotonin biosynthesis pathway [5], and the dopamine receptor subtype 3 (DRD3) [6]. These targets, although promising to variable degrees, all exhibit features complicating their use in the 
context of BCM imaging, such as species-dependent background expression in the acinar pancreas or expression in other endocrine cell subtypes [7-9]. Thus, it is of interest to identify and assess novel beta-cell restricted molecular targets to facilitate novel imaging approaches.

In addition to providing a novel technique for assessing the change in BCM in the development of metabolic disease, such imaging technology may also provide important new endpoints in pharmaceutical drug development. Given the residual remaining $\mathrm{BCM}$ in the pancreas in subjects with longstanding T2D [1], but also T1D [10, 11], the expansion of endogenous beta cells may be a possible anti-diabetic treatment. For example, GLP-1 agonism has been demonstrated to expand BCM in rodent models on group level by post-mortem pancreas analysis [12], but it is not trivial to demonstrate a similar effect in clinical studies. A sensitive BCM imaging marker could for the first time allow such a clinical endpoint, potentially opening up novel research areas also in human individuals. Also other types of beta-cell replacement technologies could benefit from a beta-cell imaging marker, for example, the relatively established intraportal transplantation of islets to subjects with T1D (where the treatment efficiency is far from optimal) [13] or emerging treatments such as transplantation of macro-encapsulated beta cells [14] or stem cell transplantation.

The current paper will review the development of current and future probes for PET imaging using the protein GPR44 as a marker for BCM.

\section{GPR44 Structure, Function, and Role as Therapeutic Target}

GPR44, also known as prostaglandin $\mathrm{D}_{2}$ receptor $2\left(\mathrm{DP}_{2}\right)$ or chemoattractant receptor-homologous molecule expressed on T-helper type 2 cells (CRTH2), is a transmembrane G-coupled receptor, activated by the endogenous prostaglandin $\mathrm{D}_{2}$. It consists of 7 transmembrane alpha helices; the crystal structure of GPR44 was recently published (Fig. 1a) [15]. GPR44

Fig. 1 Structure of GPR44 (a) and two potential small molecule PET radiotracers for GPR44 $(\mathbf{b}, \mathbf{c})$

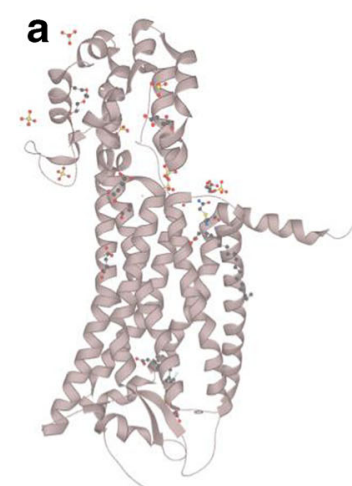

is a $\mathrm{G}$ protein-coupled receptor (GPCR) which acts negatively on cAMP production [16].

GPR44 is expressed on TH2 and eosinophil cells, and in this capacity it is involved in chemotaxis [17-19]. As the role of GPR44 in eosinophil migration was further elucidated, it emerged as a potential therapeutic target in inflammatory diseases including asthma [20]. Numerous small molecule GPR44 antagonists have therefore been developed and several of these have reached clinical testing [20]. Antagonists reaching early clinical phases include ramatroban and AMG863 (both non-selective GPR44 antagonists), OC000459, AZD1981, BI671800, and MK-7246 and more, while fevipriprant (QAW039) is currently in phase 3 [20].

In other tissues, the action of endogenous prostaglandin $\mathrm{D} 2$ $\left(\mathrm{PGD}_{2}\right)$ on GPR44 in hair follicles has been linked to hair loss alopecia [21,22], triggering research into a potential role of GPR44 antagonists as treatment for baldness [23].

\section{GPR44 Function in Beta Cells}

The function of $\mathrm{PGD}_{2}$ in the islets of Langerhans was initially discovered already in the early 1980s. The presence of endogenous $\mathrm{PGD}_{2}$ in rat islets, as well as its effects on hormone secretion, including insulin, were demonstrated in a series of publications [24-27]. These early results clearly pointed to physiologically relevant expression levels of GPR44 in beta cells, but the discovery was largely forgotten or ignored for almost 30 years.

Interest in the GPR44 expression in human islet cells was rekindled following a proteomic screening for islet restricted receptors in 2012 [28, 29•]. The screen used the Human Protein Atlas to identify proteins with strong immunostaining in the islets of Langerhans, combined with no evidence of presence in the exocrine pancreas. Further evaluation of GPR44 localization as assessed by confocal microscopy in individual human islets demonstrated co-localization between the GPR44 antibody with insulin, but not glucagon or somatostatin, indicating that the expression was restricted to beta cells $[29 \bullet, 30 \bullet \cdot$.

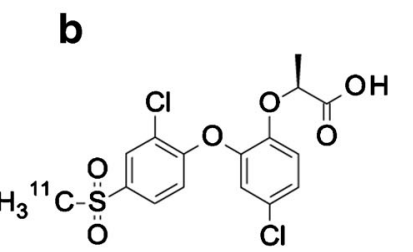

${ }^{11} \mathrm{C}-\mathrm{AZ} 12204657$

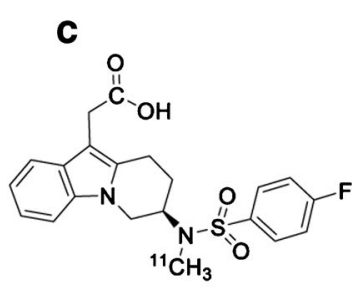

${ }^{11} \mathrm{C}-\mathrm{MK}-7246$ 
Furthermore, islets positive for insulin immunostaining were positive also for GPR44 on pancreatic sections from healthy non-diabetic human subjects, but absent in insulin negative islet in sections from subjects with T1D. In a parallel transcriptomic screen of different pancreatic compartments, it was found that GPR44 mRNA expression was 26-fold higher in islets compared to exocrine tissue [31•].

Based on the observation that GPR44 is enriched in beta cells, it is reasonable to assume a role of this protein in their cellular function. Given that GPR44 suppresses cAMP production [16], it was hypothesized that $\mathrm{PGD}_{2}$ (whether produced locally or systemically) may, via agonism at GPR44, act as a break on insulin production in response to glucose [32•]. Consequently, antagonism at the GPR44 may increase insulin secretion. Additionally, dysregulation of $\mathrm{PGD}_{2}$ signaling or GPR44 activity in beta cells may be implicated in metabolic disease.

Skrtic et al. found that $\mathrm{PGD}_{2}$ is produced by stellate cells in human islets of Langerhans, especially in T2D, providing a potential mechanism for dysregulation of insulin secretion [32•]. Furthermore, $\mathrm{PGD}_{2}$ inhibits glucose potentiation of insulin secretion in human beta-cell lines and human islets, but importantly can be normalized by co-incubation with the GPR44 antagonist AZD1981. In spite of these promising in vitro results however, therapeutic doses of AZD1981 did not affect insulin secretion in individuals with T2D in a clinical cross-over study [32•]. Thus, the association of GPR44 in the in vivo regulation of the insulin secretory machinery and possible dysfunction in human diabetes is still uncertain.

Still, both in vitro and clinical studies point to the robust expression of GPR44 in beta cells, thus constituting a putative imaging marker specifically for beta cells, given the development of ligands suitable for radiolabeling.

\section{Development of GPR44 Imaging Ligands}

As discussed above, several small molecule antagonisms have been developed for targeting of GPR44. However, ligands optimized for imaging applications have different requirements compared to those intended for therapeutic applications. For example, oral bioavailability is imperative for a drug candidate and constitutes an important feature for candidate selection, while this is largely unimportant for an intravenously administered PET ligand. Additionally, increased lipophilicity and associated increase in off-target binding may be inconsequential for a drug candidate, while non-specific in vivo binding in the PET situation may obscure any receptor-specific binding present in the tissue of interest.

AZD3825, a small molecule antagonist against GPR44, was developed by high throughput screening using a ${ }^{3} \mathrm{H}$ $\mathrm{PGD}_{2}$ displacement assay. AZD3825 is potentially suitable for imaging due to its $\mathrm{IC}_{50}$ in the nanomolar range and relatively low lipophilicity [31•]. The ligand was tritiated $\left({ }^{3} \mathrm{H}-\mathrm{AZD} 3825\right)$ and used to assess GPR44 receptor density $\left(B_{\max }\right)$ as well as affinity $\left(K_{\mathrm{d}}\right)$ in human immortalized beta cells (EndoC-BH1), islet and exocrine tissue [31•]. Its affinity was in nanomolar range in all tissues, but $B_{\max }$ was $>45$ and $>$ 6 larger in beta cells and islets respectively compared to exocrine tissue. The possibility of visualizing a target by PET depends on the interplay between both number of available receptors in tissue, as well as the affinity. The relationship is often expressed as binding potential (BP) (Eq. 1), where BP > 2 is desired for sufficient signal in tissue. As evident from Eq. 1 , low expression in tissue can be compensated for by increased affinity.

$B P=\frac{B_{\max }\left(\frac{p m o l}{m L}\right)}{K_{\mathrm{d}}(n M)}$

In beta cells, GPR44 density was measured as approximately $23 \mathrm{pmol} / \mathrm{mL}$, while affinity was $1.2 \mathrm{nM}$, yielding a $\mathrm{BP}=19.2$. On the other hand, in exocrine cells, BP was 0.3. Rat beta cells (INS-1 cell line) did not exhibit significant expression of GPR44 indicating species variation. AZD3825 was thus identified as lead compound for development of a PET tracer, for isotopic radiolabeling with Carbon-11. Using AZD3825 as starting point, a demethylated precursor for AZ12204657 (Fig. 1a) was developed [30••].

AZ12204657 was shown to displace tritiated $\mathrm{PGD}_{2}$, as well as tritiated AZ12204657 itself, dose-dependently from membranes of HEK293 cells overexpressing human GPR44 [30••]. AZ12204657 also acts as an antagonist on GPR44 as it could inhibit the $\mathrm{PGD}_{2}$ signaling in human immortalized EndoCBH1 beta cells [30••]. Demethylated AZ12204657 was then radiolabeled with Carbon- 11 by addition of ${ }^{11} \mathrm{C}-\mathrm{CH}_{3} \mathrm{I}$ as described in detail previously (Fig. 1b) [30••].

Another approach for the identification of suitable PET imaging ligands for GPR44 has included radiolabeling of some of the drugs currently or previously in clinical trials. The upside of such an approach is that the ligands are presumably thoroughly characterized (affinity, lipophilicity, protein binding, etc.) as well as tested for toxicology. On the other hand, such ligands may not be optimal for imaging, with regard to lipophilicity etc. as discussed above. MK-7246, as an example, possesses an affinity and $\mathrm{IC}_{50}$ just above the nanomolar range [33-35].

Crucially, it also contains a fluorine nuclide, which potentially can be isotopically replaced by a Fluorine-18 and thus a preferable longer radioactive half-life (Fig. 1c). Demethylated MK-7246 was also radiolabeled by addition of ${ }^{11} \mathrm{C}-\mathrm{CH}_{3} \mathrm{I}$, similar as for ${ }^{11} \mathrm{C}$-AZ12204657 [36••]. Fevipriprant is also potentially an attractive imaging ligand, given its high 
nanomolar affinity and its relatively low lipophilicity $(\log \mathrm{P}=$ 2.3) but is so far unexplored in the imaging setting [37].

The use of radiolabeled peptides and biologics such as monoclonal antibodies (mAbs) for in vivo imaging has increased during the last decades. Several mAbs directed towards human GPR44 are available for different applications including immunofluorescent in vitro imaging. It is therefore conceivable to consider radiolabeling of $\mathrm{mAbs}$ also for GPR44 in vivo molecular imaging.

However, given the slow clearance of mAbs, several days of biodistribution and clearance are usually required from administration to achieve high-contrast imaging of tissues of interest. Antibodies are therefore often radiolabeled with radionuclides with radioactive half-life in the range of days such as Zirconium-89 (PET, $t_{1 / 2}=4$ days), Indium-111 (SPECT, $t_{1 / 2}=4$ days) or Iodine-124 (PET, $t_{1 / 2}=4$ days). The substantial deposited radiation dose associated to these radionuclides does in practice preclude repeated PET or SPECT imaging in many patient groups and in healthy individuals or those with diabetes involved in research studies. In order to decrease the radionuclide half-life, and thus the absorbed dose, the biological half-life of the antibody must be decreased in some fashion, often by miniaturization of the construct. This can be achieved by, for example, using the binding domain, such as single chain variable fragments ( $\mathrm{scFv}$ ), thus in theory retaining excellent target affinity while reducing time for blood clearance. Other possibilities include directed protein engineering techniques including generations of nanobodies (relatively small camelid single domain antibodies) or affibody constructs (based on a $6.5 \mathrm{kDa}$ peptide scaffold). Such small protein constructs display more rapid biodistribution often compatible with short-liver radionuclides such as Gallium-68 or Fluorine-18. However, raising, for example, affibodies towards the relatively small extracellular domain of GPR44 may pose an issue.

Based on the possibility of precursor synthesis, as well as convenient Carbon-11 by methylation, MK7246 and AZ12204657 have so far been evaluated in vitro and in vivo for GPR44 imaging.

\section{Imaging Results_In Vitro Approaches}

The preclinical characterization of unlabeled MK7246 and AZ12204657 demonstrated high affinity and specificity to GPR44. Since both molecules were labeled isotopically by substitution of a stable Carbon-12 to a positron emitting Carbon-11 nuclide, the resulting PET tracers ${ }^{11} \mathrm{C}-\mathrm{MK} 7246$ and ${ }^{11} \mathrm{C}$-AZ12204657 should in theory behave in an identical manner as their respective unlabeled analogue (excluding any negligible kinetic isotope effects).

High islet-to-exocrine receptor binding ratio is required for any islet or beta-cell imaging agent, in order to yield sufficient contrast in imaging studies. The resolution of modern clinical PET scanners is around $3-5 \mathrm{~mm}$ and thus it is not currently possible to resolve individual islets of Langerhans in the pancreas. However, given sufficient contrast, the PET signal from each voxel will in theory represent the beta-cell density. The average beta-cell density (or average PET tracer concentration) multiplied with the total pancreatic volume will thus produce the total pancreatic BCM [2].

${ }^{11} \mathrm{C}-\mathrm{AZ} 12204657$ demonstrated strong binding to isolated human islets with a purity of $93 \%$ (Table 1). The binding was GPR44-mediated as it could be inhibited by co-incubation with GPR44 antagonist AZD3825 [30••]. The binding to pure exocrine tissue was a magnitude lower and non-specific, thus indicating a high islet-to-exocrine ratio. Islet homogenate binding studies have not yet been reported for ${ }^{11} \mathrm{C}-\mathrm{MK}-7246$.

In vitro autoradiography assays on human pancreatic sections have been performed for both ${ }^{11} \mathrm{C}-\mathrm{AZ} 12204657$ and ${ }^{11} \mathrm{C}-\mathrm{MK}-7246$ as well as for tritiated ${ }^{3} \mathrm{H}-\mathrm{AZ} 12204657 .{ }^{11} \mathrm{C}$ AZ12204657 demonstrated clear binding to focal areas of pancreas from non-diabetic donors and donors with T2D $[30 \bullet \bullet, 38 \bullet \bullet$. The focal uptake was identical to the islets of Langerhans, as demonstrated by immunofluorescent staining for insulin on adjacent sections, again demonstrating a high islet-to-exocrine binding ratio. Importantly, no binding was seen in pancreatic sections lacking positive insulin staining. The focal binding patterns were GPR44-mediated (blockable by addition of AZD23825), in line with the results from the binding studies in isolated islets. Similar results were seen for ${ }^{3} \mathrm{H}-\mathrm{AZ} 12204657$ on human pancreatic sections from nondiabetic donors [30••]. ${ }^{11} \mathrm{C}-\mathrm{MK}-7246$ also bound in clear focal patterns to human pancreatic sections from non-diabetic and T2D donors, which was likely receptor-mediated as it could be abolished by co-incubation with unlabeled MK-7246 added in excess [36••]. The focal patterns were dense especially in areas positive for insulin staining. Additional studies in T1D pancreas devoid of insulin positive islets as well as binding studies to islets and exocrine tissue should be performed for ${ }^{11} \mathrm{C}-\mathrm{MK}-7246$ to verify these initial results.

\section{Imaging Results_In Vivo PET}

Even if a PET tracer demonstrates excellent binding properties in vitro, there may be additional challenges to repeat such observations in vivo. In vitro assays are often designed to expose the tissue or receptor of interest directly to intact functional ligand at optimal conditions (correct buffer, temperature etc.). In the in vivo situation on the other hand, the PET tracer is administered peripherally, and is exposed to the organism's blood and tissues as well as many metabolic and excretionary processes, before reaching the intended target where it may bind. Thus, it is imperative to demonstrate in vivo targeting in the tissue of interest of a PET tracer, also when the in vitro 
Table 1 Overview of in vitro and in vivo evaluation of PET radiotracers for GPR44

\begin{tabular}{|c|c|c|c|c|c|}
\hline Assay & & Species & Model & ${ }^{11} \mathrm{C}-\mathrm{AZ} 12204657$ & ${ }^{11} \mathrm{C}-\mathrm{MK} 7246$ \\
\hline \multirow[t]{2}{*}{ In vitro cell binding } & Islet & Human & Healthy & High, receptor-specific & $\mathrm{N} / \mathrm{A}$ \\
\hline & Exocrine & & & Low, non-specific & N/A \\
\hline \multirow[t]{6}{*}{ In vitro autoradiography } & Pancreas & Pig & Healthy & Pancreatic binding receptor-specific & N/A \\
\hline & & & STZ T1D & No binding in pancreas & N/A \\
\hline & & Non-human primate & & Pancreatic binding receptor-specific & N/A \\
\hline & & Human & Healthy & Binding in islets, receptor-specific & $\begin{array}{l}\text { Binding in islets, } \\
\text { receptor-specific }\end{array}$ \\
\hline & & & $\mathrm{T} 2 \mathrm{D}$ & Binding in islets, receptor-specific & N/A \\
\hline & & & $\mathrm{T} 1 \mathrm{D}$ & No binding in pancreas & N/A \\
\hline In vivo targeting in mouse & Transplanted islets & Human & Healthy & Binding to islets, receptor-specific & N/A \\
\hline \multirow[t]{2}{*}{ In vivo targeting } & Pancreas & Pig & Healthy & Receptor-specific & Receptor-specific \\
\hline & & Non-human primate & Healthy & Receptor-specific & $\mathrm{N} / \mathrm{A}$ \\
\hline
\end{tabular}

results are promising. Initial in vivo targeting is often assessed in small animal models such as mouse or rat. In the case of GPR44, rat and mouse pancreatic islets do not exhibit the same strong immunostaining for this protein as that seen in human [31•] or pig (not published). Accordingly, rat beta cell derived INS-1 cells showed negligible binding of ${ }^{3} \mathrm{H}$ AZD3825 [31•]. Thus, rat and mouse pancreas are not expected to provide a suitable model for GPR44 targeting PET tracers that translate to large animals and the clinical situation. A humanized mouse model can in this situation be generated, by transplanting human islets of Langerhans to immunedeficient mice. In a model where human islets where allowed to engraft in the kidney capsule, ${ }^{11} \mathrm{C}$-AZ12204657 demonstrated strong binding in the capsule containing islets, but negligible binding in the contralateral non-transplanted kidney capsule (Table 1) [38••]. Also in vivo the binding could be abolished by pre-treatment with $4 \mathrm{mg} / \mathrm{g}$ AZD3825.

In vitro autoradiography demonstrated focal binding patterns for ${ }^{11} \mathrm{C}$-AZ12204657 in pancreas from nondiabetic pig, consistent with immunohistochemical staining for insulin on adjacent sections [38••], and the previously demonstrated expression of GPR44 in pig islets (unpublished data). Importantly, beta-cell deficient pancreas sections from pigs treated by streptozotocin were negative for ${ }^{11} \mathrm{C}$-AZ12204657 binding. Accordingly, PET/MRI imaging with ${ }^{11} \mathrm{C}$-AZ12204657 in pig showed binding in pancreas, which could be competed away dose-dependently. Pre-treatment with $5 \mathrm{mg} / \mathrm{kg}$ GPR44 antagonist AZ8154 reduced the pancreatic binding by around $60 \%$. Interestingly, significant ${ }^{11} \mathrm{C}$-AZ12204657 binding, blockable by on average $86 \%$, was also seen in pig spleen, which was verified by in vitro autoradiography of pig splenic sections. The splenic binding is not expected to occur in humans in vivo, based on in vitro autoradiographic studies of human splenic sections [38••]. ${ }^{11} \mathrm{C}-\mathrm{MK}-7246$ was evaluated in pigs by $\mathrm{PET} / \mathrm{CT}$, where significant binding similarly was seen in pancreas and spleen [36••]. The binding was reduced following pre-treatment with $1 \mathrm{mg} / \mathrm{kg}$ unlabeled MK-7246, by $66 \%$ in pancreas and $88 \%$ in spleen. It is interesting that the GPR44 receptor mediated in pancreas (60 vs. 66\%) and splenic (86 vs. $88 \%$ ) binding is so similar for the different PET tracers, indicating a similar mechanism of binding, as expected. The excretion of both tracers in pig was primarily through bile excretion into the intestines.

${ }^{11} \mathrm{C}-\mathrm{AZ} 12204657$ was also evaluated in cynomolgus non-human primates (NHP) by PET/CT. As in pigs, binding was demonstrated in both pancreas and to a lesser extent spleen, and the binding in both tissues could be abolished by pre-treatment by $1 \mathrm{mg} / \mathrm{kg}$ of GPR44 antagonist AZD3825 [38••]. The GPR44-mediated mechanism could be corroborated by in vitro autoradiography studies on pancreatic sections from NHP with and without blocking agent AZD3825, and co-staining for insulin [30••]. However, the strong signal from radioactive metabolites excreted into the intestines tended to cause spill in of signal into the pancreas, in particular the head and body. Thus, the NHP binding data is mainly based on ${ }^{11} \mathrm{C}$ AZ12204657 binding in the pancreas tail. This issue was likely due to the small size of the animals (around $5 \mathrm{~kg}$ ) and small distance between intestines and pancreas in comparison with the PET/CT scanner resolution. The same issue was not seen in pigs (around $25 \mathrm{~kg}$ ) and is not expected to cause any issues in potential future ${ }^{11} \mathrm{C}-\mathrm{AZ} 12204657$ scanning in humans.

Biodistribution studies was performed in rat by small animal PET/MRI scanning for ${ }^{11} \mathrm{C}-\mathrm{MK}-7246$, to extrapolate the predicted radiation dose in humans [36••]. The excretion occurred mainly through the liver, biliary systems, and the intestines, as seen for both ${ }^{11} \mathrm{C}-\mathrm{MK}-7246$ in pig and for ${ }^{11} \mathrm{C}-\mathrm{AZ} 12204657$ in both pig and NHP. The rat derived dosimetry is thus likely representative to human, even if the pancreas dose may be 
underestimated given the lack of specific binding to GPR44 in rodent islets. As expected, the absorbed dose associated with a Carbon-11 labeled molecule was low and compatible with several repeated PET/CT examinations annually [36••].

\section{Future Perspectives and Comparison with Other Beta-Cell Imaging Approaches}

As outlined in the "Introduction," there exist several different interesting putative molecular targets suggested as surrogate markers for beta cell or islet mass. The merits and challenges of each of the targets have been discussed in detail previously. Direct comparison with GPR44 targeting tracers may be premature and pending evaluation of ${ }^{11} \mathrm{C}-\mathrm{AZ} 12204657$ or ${ }^{11} \mathrm{C}$ MK-7246 in human studies.

It is important to note that the different performance of various imaging agents may represent different features of the endocrine pancreas and not simply the BCM. Serotonin marker ${ }^{11} \mathrm{C}-5$ hydroxytryptophan, for example, may be a tool indicative of total endocrine mass and provide value especially in combination with a beta-cell specific marker - i.e., to provide an endpoint, for example, for de-differentiation of beta cells into endocrine progenitor cells [5]. Similarly, VMAT2, GLP1R, and GPR44 imaging may all provide insights into different parts of beta-cell change in function or mass, depending on increased understanding of the role of respective receptor system in the endocrine pancreas.

Some general comments can be made regarding the different classes of ligand available for each target. VMAT2 imaging is currently dominated by Flurine-18 labeled small molecules which potentially enables important assays such as ex vivo autoradiography in animals, or optimized use of radiochemistry batches by scanning of several individuals or even shipping of PET tracer to remote sites. GLP1R imaging is currently performed by using different peptide constructs based on the Exendin-4 sequence to different degrees. Peptides can be radiolabeled with both Gallium- 68 and Fluorine-18 but the clinical reality in the case of Exendin-based PET imaging is that Gallium-68 is commonly used. The practical logistical issues with Gallium-68 generally preclude the shipping of PET batches between sites and sharing of batches between patients. Additionally, there are dosimetric challenges associated with Gallium-68-labeled peptides, as the retention of the radioactive label in the renal cortex specifically makes the absorbed dose to the kidney a limiting factor. This is especially challenging in patient groups with different stages of renal dysfunction.

In this context, Carbon-11 labeled small molecules such as ${ }^{11} \mathrm{C}-\mathrm{AZ} 12204657$ and ${ }^{11} \mathrm{C}-\mathrm{MK}-7246$ may provide an advantage given the limited deposited dose and the hepatic route of excretion. Carbon-11 has such a short radioactive half-life of only $20 \mathrm{~min}$, that the associated radioactivity has largely disappeared only $2 \mathrm{~h}$ after administration. In combination with a beneficial dosimetry profile, this allows for individual patients to be examined several times during the course of a day, for example, to investigate drug targeting of the GPR44 receptor. However, the short half-life of Carbon-11 also precludes the possibility of sharing batches between patients or performing preclinical validation assays such as in ex vivo autoradiography studies. Thus, Fluorine-18 labeling of GPR44 targeting molecules is the next logical step in development. MK-7246 is in this framework especially promising given that it comprises a fluorine atom in a position theoretically available for radiolabeling (Fig. 1c).

An outstanding question for GPR44 targeting PET ligands are other uses besides imaging of beta cells, including its potential application as a marker for neuroendocrine tumors, especially insulinoma (i.e., beta-cell derived tumors). It is reasonable to expect a possible use in this field but currently no data is available on the GPR44 expression on insulinoma cells.

\section{Conclusion}

Available studies indicate that GPR44 represents an attractive target for visualization of BCM. Several small molecule antagonists have been radiolabeled and evaluated up to large animal models. Further progress in radioligand development, including Fluorine-18 radiolabeling and clinical testing is expected to clarify their use as surrogate markers for BCM in human health and disease.

\section{Compliance with Ethical Standards}

Conflict of Interest Olof Eriksson is an employee of Antaros Medical $\mathrm{AB}$, otherwise he declares no conflict of interest.

Human and Animal Rights and Informed Consent This article does not contain any studies with human or animal subjects performed by any of the authors.

Open Access This article is distributed under the terms of the Creative Commons Attribution 4.0 International License (http:// creativecommons.org/licenses/by/4.0/), which permits unrestricted use, distribution, and reproduction in any medium, provided you give appropriate credit to the original author(s) and the source, provide a link to the Creative Commons license, and indicate if changes were made.

\section{References}

Papers of particular interest, published recently, have been highlighted as:

- Of importance

-• Of major importance

1. Rahier J, Guiot Y, Goebbels RM, Sempoux C, Henquin JC. Pancreatic beta cell mass in European subjects with type 2 diabetes. Diabetes Obes Metab. 2008;10:32-42. 
2. Eriksson O, Laughlin M, Brom M, Nuutila P, Roden M, Hwa A, et al. In vivo imaging of beta cells with radiotracers: state of the art, prospects and recommendations for development and use. Diabetologia. 2016;59:1340-9.

3. Normandin MD, Petersen KF, Ding Y-S, Lin S-F, Naik S, Fowles $\mathrm{K}$, et al. In vivo imaging of endogenous pancreatic -cell mass in healthy and type 1 diabetic subjects using 18F-fluoropropyldihydrotetrabenazine and PET. J Nucl Med. 2012;53:908-16.

4. Brom M, Woliner-Van Der Weg W, Joosten L, Frielink C, Bouckenooghe T, Rijken P, et al. Non-invasive quantification of the beta cell mass by SPECT with 111In-labelled exendin. Diabetologia. 2014;57:950-9.

5. Carlbom L, Espes D, Lubberink M, Martinell M, Johansson L, Ahlström $\mathrm{H}$, et al. $\left[{ }^{11} \mathrm{C}\right] 5$-hydroxy-tryptophan pet for assessment of islet mass during progression of type 2 diabetes. Diabetes. 2017;66:1286-92.

6. Bini J, Naganawa M, Nabulsi N, Huang Y, Ropchan J, Lim K, et al. Evaluation of PET brain Radioligands for imaging pancreatic $\beta$-cell mass: potential utility of ${ }^{11} \mathrm{C}-(+)-P H N O$. J Nucl Med. 2018;59: 1249-54.

7. Eriksson O, Rosenström U, Selvaraju RK, Eriksson B, Velikyan I. Species differences in pancreatic binding of DO3A-VS-Cys ${ }^{40}$ Exendin4. Acta Diabetol. 2017;54:1039-45.

8. Freeby M, Ichise M, Harris PE. Vesicular monoamine transporter, type 2 (vmat2) expression as it compares to insulin and pancreatic polypeptide in the head, body and tail of the human pancreas. Islets. 2012;4:393-7.

9. Eriksson O, Selvaraju RK, Johansson L, Eriksson JW, Sundin A, Antoni G, et al. Quantitative imaging of serotonergic biosynthesis and degradation in the endocrine pancreas. J Nucl Med. 2014;55: $460-5$.

10. Keenan HA, Sun JK, Levine J, Doria A, Aiello LP, Eisenbarth G, et al. Residual insulin production and pancreatic $\beta$-cell turnover after 50 years of diabetes: Joslin medalist study. Diabetes. 2010;59:2846-53.

11. Espes D, Singh K, Sandler S, Carlsson PO. Increased interleukin-35 levels in patients with type 1 diabetes with remaining c-peptide. Diabetes Care. 2017;40:1090-5.

12. Xu G, Stoffers DA, Habener JF, Bonner-Weir S. Exendin-4 stimulates both $\beta$-cell replication and neogenesis, resulting in increased $\beta$-cell mass and improved glucose tolerance in diabetic rats. Diabetes. 1999;48:2270-6.

13. Shapiro AMJ, Ricordi C, Hering BJ, Auchincloss H, Lindblad R, Robertson RP, et al. International trial of the Edmonton protocol for islet transplantation. N Engl J Med. 2006;355:1318-30.

14. Carlsson PO, Espes D, Sedigh A, Rotem A, Zimerman B, Grinberg $\mathrm{H}$, et al. Transplantation of macroencapsulated human islets within the bioartificial pancreas $\beta$ Air to patients with type 1 diabetes mellitus. Am J Transplant. 2018;18:1735-44.

15. Wang L, Yao D, Deepak RNVK, Liu H, Xiao Q, Fan H, et al. Structures of the human PGD 2 receptor CRTH2 reveal novel mechanisms for ligand recognition. Mol Cell. 2018;72:48-59.

16. Hata AN. Expression and molecular pharmacology of the mouse CRTH2 receptor. J Pharmacol Exp Ther. 2003;306:463-70.

17. Nagata K, Tanaka K, Ogawa K, Kemmotsu K, Imai T, Yoshie O, et al. Selective expression of a novel surface molecule by human Th2 cells in vivo. J Immunol. 1999;162:1278-86.

18. Tsuda H, Michimata T, Sakai M, Nagata K, Nakamura M, Saito S. A novel surface molecule of Th2- and Tc2-type cells, CRTH2 expression on human peripheral and decidual CD4+ and CD8+ T cells during the early stage of pregnancy. Clin Exp Immunol. 2001;123: 105-11.

19. Hirai H, Tanaka K, Yoshie O, Ogawa K, Kenmotsu K, Takamori Y, et al. Prostaglandin D2 selectively induces chemotaxis in T helper type 2 cells, eosinophils, and basophils via seven-transmembrane receptor CRTH2. J Exp Med. 2001;193:255-61.
20. Kupczyk M, Kuna P. Targeting the $\mathrm{PGD}_{2} / \mathrm{CRTH} 2 / \mathrm{DP} 1$ signaling pathway in asthma and allergic disease: current status and future perspectives. Drugs. 2017;77:1281-94.

21. Garza LA, Liu Y, Yang Z, Alagesan B, Lawson JA, Norberg SM, et al. Prostaglandin D 2 inhibits hair growth and is elevated in bald scalp of men with androgenetic alopecia. Sci Transl Med. 2012;4: 126 ra34.

22. Joo HW, Kang YR, Kwack MH, Sung YK. 15-deoxy prostaglandin $\mathrm{J} 2$, the nonenzymatic metabolite of prostaglandin D2, induces apoptosis in keratinocytes of human hair follicles: a possible explanation for prostaglandin D2-mediated inhibition of hair growth. Naunyn Schmiedeberg's Arch Pharmacol. 2016;389:809-13.

23. Nieves A, Garza LA. Does prostaglandin D2 hold the cure to male pattern baldness? Exp Dermatol. 2014;23:224-7.

24. Horie H, Matsuyama T, Namba M, Nonaka K, Tarui S. Modulation by prostaglandin D2 of glucagon and insulin secretion in the perfused rat pancreas. Prostaglandins Leukot Med. 1983;12:315:321.

25. Evans MH, Pace CS, Clements RS. Endogenous prostaglandin synthesis and glucose-induced insulin secretion from the adult rat pancreatic islet. Diabetes. 1983;32:509-15.

26. Matsuyama T, Horie H, Namba M, Nonaka K, Tarui S. Glucose dependent stimulation by prostaglandin D2 of glucagon and insulin in perfused rat pancreas. Life Sci. 1983;32:979-82.

27. Horie H, Narumiya S, Matsuyama T, Nonaka K, Tarui S. Presence of prostaglandin D2, E2 AND F2 $\alpha$ in rat pancreatic islets. Prostaglandins Leukot Med. 1984;16:39-44.

28. Lindskog C, Asplund A, Engkvist M, Uhlen M, Korsgren O, Ponten F. Antibody-based proteomics for discovery and exploration of proteins expressed in pancreatic islets. Discov Med. 2010;9: 565-78.

29. Lindskog C, Korsgren O, Pontén F, Eriksson JW, Johansson L, Danielsson A. Novel pancreatic beta cell-specific proteins: antibody-based proteomics for identification of new biomarker candidates. J Proteome. 2012;75:2611-20. The study describes GPR44 as a beta-cell restricted protein, not previously reported as expressed in pancreas.

30.• Jahan M, Johnström P, Selvaraju RK, Svedberg M, Winzell MS, Bernström J, et al. The development of a GPR44 targeting radioligand $\left[{ }^{11}\right.$ C]AZ12204657 for in vivo assessment of beta cell mass. EJNMMI Res. 2018;8:113. The study describes the detailed method for synthesis of the first GPR44 targeting PET radioligand.

31. Hellström-Lindahl E, Danielsson A, Ponten F, Czernichow P, Korsgren O, Johansson L, et al. GPR44 is a pancreatic protein restricted to the human beta cell. Acta Diabetol. 2016;53:413-21. The study describes the assessment of GPR44 receptor densities in human beta cells, islets, and exocrine tissue. It also identifies AZD3825 as a lead compound for PET tracer development.

32. Skrtic S, Tyrberg B, Broberg M, Ericsson H, Schnecke V, Kjaer M, et al. Exploring the insulin secretory properties of the PGD 2 GPR44/DP2 axis in vitro and in a randomized phase-1 trial of type 2 diabetes patients. PLoS One. 2018;13:e0208998. The clinical study assessing the efficacy of a GPR44 antagonist in treatment of T2D.

33. Molinaro C, Bulger PG, Lee EE, Kosjek B, Lau S, Gauvreau D, et al. CRTH2 antagonist MK-7246: a synthetic evolution from discovery through development. J Org Chem. 2012;77:2299-309.

34. Gervais FG, Sawyer N, Stocco R, Hamel M, Krawczyk C, Sillaots S, et al. Pharmacological characterization of MK-7246, a potent and selective CRTH2 (chemoattractant receptor-homologous molecule expressed on T-helper type 2 cells) antagonist. Mol Pharmacol. 2010;79:69-76.

35. Gallant M, Beaulieu C, Berthelette C, Colucci J, Crackower MA, Dalton C, et al. Discovery of MK-7246, a selective CRTH2 antagonist for the treatment of respiratory diseases. Bioorg Med Chem Lett. 2011;21:288-93. 
36.• Eriksson J, Roy T, Sawadjoon S, Bachmann K, Sköld C, Larhed M, et al. Synthesis and preclinical evaluation of the $\mathrm{CRTH} 2$ antagonist [11C]MK-7246 as a novel PET tracer and potential surrogate marker for pancreatic beta-cell mass. Nucl Med Biol. 2019;71:1-10. The study describes the detailed method for synthesis of GPR44 targeting PET radioligand MK7246.

37. Sykes DA, Bradley ME, Riddy DM, Willard E, Reilly J, Miah A, et al. Fevipiprant (QAW039), a slowly dissociating CRTh2 antagonist with the potential for improved clinical efficacy. Mol Pharmacol. 2016;89:593-605.
38.• Eriksson O, Johnström P, Cselenyi Z, Jahan M, Selvaraju RK, Jensen-Waern $\mathrm{M}$, et al. In vivo visualization of $\beta$-cells by targeting of GPR44. Diabetes. 2018;67:182-92. The study describes the detailed in vivo evaluation of PET radioligand AZ12204657, demonstrating high precision assessment of GPR44 in pancreas.

Publisher's Note Springer Nature remains neutral with regard to jurisdictional claims in published maps and institutional affiliations. 